\title{
Maxillofacial Radiology 164
}

SADJ September 2018, Vol. 73 No. 8 p527

CJ Nortjé

A four year old female presented with the main complaint of limited opening of the mouth (Fig. 1). She appears to have some form of discomfort when eating her food and according to her mother this problem started shortly after birth and has not received any form of treatment. What is your diagnosis?
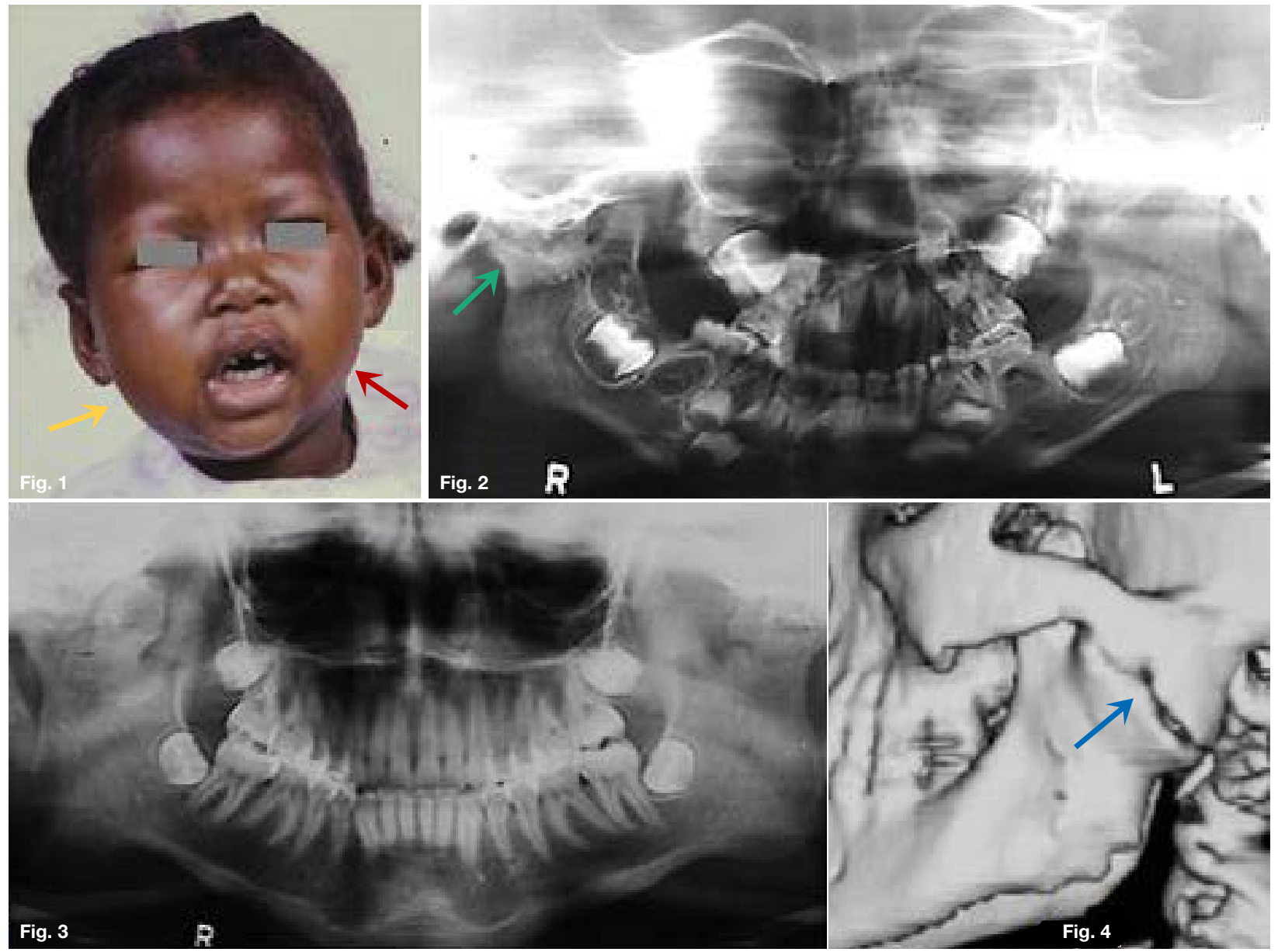

INTERPRETATION

The pantomograph (Fig.2) shows irregular radiopacity representing an extra-articular ankylosis of the temporomandibular joint region and lack of joint space on the right side (green arrow). A diagnosis of osseous ankylosis of the TMJ was made, which is the bony union of the mandibular condyle with part of the temporal bone, resulting in immobility of the joint. Ankylosis of the TMJ is one of the most incapacitating of all diseases involving this structure. The most frequent causes of ankylosis of the TMJ are traumatic injuries and infections in and about the joint. Infections commonly result in inflammatory destruction of the synovial lining of the joint, resulting in contact between the underlying osseous structures. The inflammation may result from primary infection of the joint; extension from a neighbouring infection such as otitis media, mastoiditis, or osteomyelitis of the mandible; blood-borne infections from several sources; trauma to the joint; or one of the rheumatoid arthritis, ankylosing spondylitis; psoriatic arthritis and Reiter syndrome. True ankyloses between the condyle and temporal bone manifest as a painless inability to open the mouth properly.

CJ Nortjé: BChD, PhD, ABOMR, DSc. Faculty of Dentistry, University of the Western Cape. E-mail: cnortje@uwc.ac.za
The degree of inability is variable, because the bone of the mandible is somewhat flexible; thus even with bilateral ankyloses there is not complete lack of movement of bone. In unilateral cases there is usually a fullness of the face on the affected side (Fig.1 yellow arrow), and flattening of the face on the unaffected side, (Fig.1 red arrow). Deviation of the midline toward the affected side may also be present, a result of unilateral growth. If the ankylosis is bilateral (Fig.3) and has been present before the end of somatic growth, retrognathia and downward growth of the mandible may be present. A 3-D reformatted CT scan (Fig.4) shows a mass of bone extending laterally from the ramus, joining the condyle to the borders of the glenoid fossa (blue arrow). This is pathognomic of bilateral osseous ankylosis of the TMJ. Treatment of osseous ankylosis consists of osteotomy and removal of a section of bone below the condyle. Fibrous ankylosis may be treated by functional methods.

\section{References:}

1. Farman AG, Nortje CJ \& Wood RE: Oral and Maxillofacial Imaging $1^{\text {st }}$ Ed. Mosby, St. Louis. Missouri, 1993 p 354-6.

2. Shafer WG, Hine MK\& Levy BM: A Textbook of Oral Pathology



